Journal of Sport and Exercise Psychology, (Ahead of Print) https://doi.org/10.1123/jsep.2019-0260

\title{
Fitness-Related Self-Conscious Emotions and Risk for Exercise Addiction: Examining the Mediating Role of Passion
}

Alvaro Sicilia, ${ }^{1}$ Manuel Alcaraz-Ibáñez, ${ }^{1}$ Delia C. Dumitru, ${ }^{1}$ Adrian Paterna, ${ }^{1}$ and Mark D. Griffiths ${ }^{2}$

${ }^{1}$ University of Almería; ${ }^{2}$ Nottingham Trent University

Abstract

3 Fitness-related self-conscious emotions (SCEs) have been proposed as antecedents of exercise

4 addiction. However, the potential mechanisms underlying such a relationship remain

5 unexplored. The present study examined the relationship between fitness-related SCEs and risk

6 of exercise addiction (EA) by examining the mediating role of passion for exercise. A total of

7296 male runners $(M=40.35$ years; $S D=10.69)$ completed a survey assessing weekly exercise

8 frequency/hours, fitness-related SCEs, passion for exercise, and the risk of EA. The

9 relationships between the study variables were examined utilizing structural equation

10 modeling. After controlling for age and weekly exercise frequency/hours, fitness-related SCEs

11 of shame, guilt, and hubristic pride were positively associated with risk of EA. However, while

12 guilt had direct effects on risk of EA, shame and hubristic pride showed indirect effects via

13 obsessive passion. The results of the study are discussed, and some practical implications and

14 future research directions are presented.

15

16 Keywords: body image; guilt; shame; pride; exercise addiction, exercise dependence 
Fitness-Related Self-Conscious Emotions and Risk for Exercise Addiction: Examining the

\section{Mediating Role of Passion}

Exercise addiction (EA) is a possible behavioral disorder that involves exercising in a way that is difficult to control or reduce, and presents physiological symptoms (e.g., tolerance, withdrawal) and/or psychological symptoms (e.g., anxiety, depression) (Hausenblas \& Symons-Downs, 2002). Although EA is still not a recognized disorder in the main diagnostic classifications (e.g., DSM-5; American Psychiatric Association, 2013; ICD-11; World Health Organization, 2018), interest in its study has been growing because of its association with physical, social, and psychological negative consequences ( Hausenblas \& Symons-Downs, 2002; Szabo, Demetrovics, \& Griffiths, 2018). Given its potentially harmful consequences, understanding the factors that trigger EA is of interest in both preventing and treating this possible disorder.

Self-conscious emotions (SCEs) have been proposed to have a central role in in explaining individual's behavior in achievement contexts such as exercise (Castonguay, Pila, Wrosch, \& Sabiston, 2015; Castonguay, Sabiston, Kowalski, \& Wilson, 2016). When it comes to examining exercise behavior, research on SCEs has focused on self-relevant domains such as body experiences (Castonguay et al., 2015; Castonguay, Sabiston, Crocker, \& Mack, 2014; Tracy \& Robins, 2007b). Body-related SCEs reflect evaluative experiences concerning how individuals perceive, feel, think, and behave regarding their bodies, and how they can be experienced in reference to appearance (i.e., what the body looks like) and functional aspects of the body (i.e., how the body performs) (Castonguay et al., 2015, 2014; Tagney \& Tracy, 2012; Tracy \& Robins, 2004). Their elicitation requires stable self-representations and selfevaluations of an individual's own body, relative to internal and external standards (Robins \& Schriber, 2009). Through this self-evaluation process, individuals compare their current selfrepresentation (i.e., how individuals see themselves now) with their ideal self-representation 
43 individuals appraise their current self-representation as either congruent or incongruent with

44 their ideal self-representations.

Shame and guilt have been considered as negative SCEs insofar they reflect a

46 discrepancy with respect to the (body) ideal with which an individual identifies. In both

47 negative SCEs, individuals attribute the cause of the event to some internal factor, blaming

48 themselves for the situation (Robins \& Schriber, 2009; Tagney \& Tracy, 2012; Tracy \& Robins,

49 2004). However, shame and guilt can be differentiated based on the stability and globality of

50 the causal attributions. Therefore, shame involves negative feelings about individual

51 characteristics that are uncontrollable (e.g., individuals perceiving that they are not

attractive/fit), whereas guilt involves negative feelings of individual behavior that are appearance/fitness).

Unlike shame and guilt, pride has been considered as a positive SCE because it is elicited

56 by appraisals that are relevant and congruous with the identity's goal (e.g., body ideal) (Tagney

$57 \&$ Tracy, 2012). However, as with shame and guilt, pride can also present two different facets according to the stability and globality of the causal attributions (Tracy \& Robins, 2007a). Therefore, feelings of authentic pride are based on achievements derived from the individual's own behavior (e.g., looking good or being fit as a result of following a healthy diet and

61 exercising regularly). Conversely, feelings of hubristic pride result from attributing these achievements to internal and stable causes, so that individuals evaluate themselves as better or superior to others (e.g., looking better or being fitter than others).

Although previous research has associated negative basic emotions (e.g., anger, anxiety) with risk of EA (Hausenblas \& Symons-Downs, 2002), a study by Ertl et al. (2018)

66 examined the association between body-related SCEs and risk of EA and found that body 67 shame positively predicted risk of EA, both directly and indirectly (mediated via self-esteem).

68 These results suggest that women who are at risk of developing EA may not necessarily 
experience low self-esteem while using exercise as a means of coping with, or compensating for, the negative evaluation they make of their bodies. Although the results of the Ertl et al. study are of interest, three limitations should be noted. First, this study only comprised a sample of undergraduate women, meaning further studies are necessary to examine the relationship between body-related SCEs and risk of EA in other populations (e.g., males, athletes). Second, the study did not consider positive SCEs although a recent study reported that positive body image encompasses unique features for the study of health-related variables such as exercise (Castonguay et al., 2014). Third, the study assessed an appearance-related SCE (i.e., body shame) and therefore did not consider other facets of body assessment that might explain risk of EA more fully. In fact, recent research has shown that that fitness-related aspects is a subdomain of body-related SCEs that might better explain exercise behavior than the appearance-related subdomain (Castonguay, Gilchrist, Mack, \& Sabiston, 2013; Castonguay et al., 2016; Gilchrist, Pila, Castonguay, Sabiston, \& Mack, 2018). In addition to addressing the aforementioned limitations of the Ertl et al.'s (2018) study, the present study attempts to further advance our understanding of the relationship between the SCEs and risk of EA by considering the motivational process which might explain how these emotions may be associated with risk of EA. In fact, in the psychological literature, it has been suggested that body-related SCEs may underlie the motivational regulation of exercise behavior. (e.g., Gilchrist, Sabiston, Conroy, \& Atkinson, 2018; Mack, Kouali, Gilchrist, \& Sabiston, 2015; Sabiston et al., 2010). Similarly, research has shown that individuals who exercise for reasons that are more self-determined or autonomous (i.e., by choice or motives consistent with their identity goals), such as being healthier or learning new techniques, report a more positive body image and greater adherence to exercise than individuals exercising for controlled reasons or less self-determined motivation (i.e., deriving from internal pressure or external forces) such as appearance-related goals (Sabiston et al., 2010). Considering that exercise may be a reparative behavior of the immediate and salient feedback derived from 
95 fitness-related SCEs (Castonguay et al., 2016; Mack et al., 2015), there is a possibility that the

96 relationship between such emotions and risk of EA could be affected by the motivational

97 process through which the individual is involved in exercise behavior. A construct that reflects

98 the motivational process in activities that involve intense and persistent participation, and

99 which might help explain the associations between fitness-related SCEs and EA, is the

100 construct of passion (Vallerand, 2015).

101 The Dualistic Model of Passion (DMP) proposed by Vallerand and colleagues

102 (Vallerand, 2008, 2012, 2015; Vallerand et al., 2003) has been widely applied to the exercise

103 context (De la Vega, Parastatidou, Ruíz-Barquín, \& Szabo, 2016; Kovacsik et al., 2018;

104 Parastatidou, Doganis, Theodorakis, \& Vlachopoulos, 2014; Sicilia, Alcaraz-Ibáñez, Lirola,

105 Burgueño, \& Maher, 2018; Szabo, Griffiths, et al., 2018; Vallerand, 2012). From the DMP

106 perspective, passion is defined as a strong inclination toward an activity that individuals like,

107 that they find important, invest time in, and which defines part of their identity (Vallerand et

108 al., 2003). The DMP posits that two types of passion can be differentiated according to the

109 specific form in which the activity individuals feel passion for is internalized into their identity

110 (Vallerand, 2008, 2015).

111 In the context of exercise, harmonious passion (HP) reflects an autonomous

112 internalization of exercise which occurs when individuals have freely accepted exercise as

113 important to them without any contingencies attached to it (Vallerand, 2012, 2015). Thus,

114 individuals do not feel compelled or forced to exercise but rather choose to do it freely, being

115 in control of the activity and deciding when to do it, in such a way that they make it

116 harmonious with other life domains. Individuals who manifest HP towards exercise should be

117 in a position to concentrate on the activity and experience positive affect, psychological

118 wellbeing, and task satisfaction ( Curran, Hill, Appleton, Vallerand, \& Standage, 2015;

119 Vallerand, 2008). Conversely, obsessive passion (OP) results from a controlled internalization

120 of an activity within the individual's identity (Vallerand, 2012, 2015). Controlled 
121 internalization is produced by intrapersonal and/or interpersonal pressure deriving from

122 contingencies attached to the exercise. Individuals who show OP eventually display a rigid

123 persistence towards the exercise so that they experience an internal uncontrollable urge to

124 engage in it, integrating the exercise practice into other life activities in a more rigid and

125 conflicted way. OP has been associated positively with conflict between life activities, negative

126 emotions, and risk of EA (De la Vega et al., 2016; Kovacsik et al., 2018; Marsh et al., 2013;

127 Parastatidou et al., 2014; Sicilia et al., 2018; Vallerand et al., 2003).

128 According to DMP, the interpretation of social context plays a key role in the quality of

129 the internalization process and, consequently, in the type of passion for exercise that

130 individuals develop (Vallerand, 2015). Therefore, there is a possibility that individuals who feel

131 forced to exercise to meet socially expectations in terms of physical fitness could develop a

132 low-quality internalization or a controlled internalization process. Contrary to this, the fact that

133 individuals do not feel forced to meet a given social standard in terms of physical fitness may

134 lead them to act in an autonomous way, so that exercising is internalized autonomously (i.e.,

135 devoid of external contingencies) in the individual's identity. In this regard, the elicitation of

136 fitness-related SCEs may be considered an element rooted in the interpretation that individuals

137 make from their social context which will affect the regulation of exercise behavior. Fitness-

138 related SCEs are elicited through a self-evaluation process where individuals compare their

139 current and ideal self-representations of fitness. However, as Leary (2007) suggests, SCEs are

140 much more strongly associated with what individual thinks other individuals think than what

141 individuals think of themselves, which can result in either an autonomous or controlled

142 interpretation of the social context. Individuals who elicit negative fitness-related SCEs as a

143 consequence of appraising the incongruence between their current self-representation and their

144 ideal self-representation might feel a pressure to exercise as a way to live up to socially

145 sanctioned standards, ideals, and expectations about fitness. These negative fitness-related

146 SCEs reflect a process of internal control which implies a controlled interpretation of the social 
147 context that would affect the internalization process of the behavior into the individual's 148 identity.

Although research has indicated that the type of passion for exercise helps explain risk

151 research has examined the relationship between fitness-related SCEs and risk of EA, via the

152 mediating role of passion for exercise. However, this appears to be endorsed by previous

153 studies that have considered both positive and negative SCEs, and their differentiated results

154 (Castonguay et al., 2016; Ertl et al., 2018; Sabiston et al., 2010).

155 Shame has been shown to have a positive association with risk of EA (Ertl et al., 2018).

156 In turn, this emotion has shown to have a positive correlation with guilt (Castonguay et al.,

157 2016), and both have been associated with maladaptive outcomes (Castonguay et al., 2016;

158 Sabiston et al., 2010). In fact, both shame and guilt involve negative feelings and a specific

159 blaming of the self for the situation or event assessed (Robins \& Schriber, 2009; Tagney \&

160 Tracy, 2012; Tracy \& Robins, 2004). Previous research has demonstrated that individuals

161 experiencing a feeling of blame for not being able to exercise are likely to reflect a controlled

162 internalization of the exercise and a rigid persistence towards this activity (Parastatidou et al.,

163 2014; Sicilia et al., 2018). Therefore, among these individuals, EA may be a way of coping

164 with the stress that these negative fitness-related SCEs (i.e., shame and guilt) would produce

165 (Szabo, Demetrovics, et al., 2018).

In the case of fitness-related pride, previous research has shown a positive association

167 between both facets of pride and exercise (Gilchrist, Pila, et al., 2018). However, each facet of

168 pride appears to reflect a different interpretation of the social context that might explain the

169 way in which exercise is internalized into an individual's identity and how exercise can become

170 addictive (De la Vega et al., 2016; Kovacsik et al., 2018; Parastatidou et al., 2014). Hubristic

171 pride reflects positive affect by considering oneself superior to others, and which guides

172 individuals to focus egotistically on goal-seeking at the expense of other individuals involved 
173 in that activity (Castonguay et al., 2016; Mack et al., 2015). Consequently, hubristic pride

174 reflects an important need to succeed that derives from high self-worth contingencies, a

175 characteristic that has been described in individuals with higher OP (Mageau, Carpentier, \&

176 Vallerand, 2011). Therefore, it is probable that feelings of arrogance and superiority towards

177 others reflect pressure to maintain a social status and, consequently, this controlled

178 interpretation of the social context leads the individual towards OP for exercise (Vallerand,

179 2012), which in turn has been associated with increased risk of developing EA (De la Vega et

180 al., 2016; Kovacsik et al., 2018; Sicilia et al., 2018). Furthermore, hubristic pride has been

181 associated with narcissistic personality traits, perfectionism, and low agreeableness

182 (Castonguay et al., 2013; Tagney \& Tracy, 2012), traits that are also observed in obsessive self-

183 centered behaviors leading to risk of EA (Cook, Griffiths, \& Pontes, 2018).

184 In contrast, authentic pride has generally been associated with adaptive behaviors

185 (Castonguay et al., 2016; Sabiston et al., 2010) and is therefore more likely to be related to

186 healthy ways of exercising. This might be because feelings of confidence and accomplishment

187 that can be found among individuals who feel authentic pride would reflect an autonomous

188 interpretation of the social context and would promote harmonious exercise internalization.

189 During exercise, harmoniously passionate individuals are likely to feel confident because their

190 sense of achievement is not contingent on successful exercise outcomes (Mageau et al., 2011).

191 They are also more likely to feel accomplished because they tend to reach high exercise

192 proficiency levels. Moreover, authentic pride seeks success mainly by mastering goals (Tagney

193 \& Tracy, 2012; Tracy \& Robins, 2007b) which does not appear to predict risk of EA

194 (González-Cutre \& Sicilia, 2012).

195 Based on the aforementioned empirical and theoretical literature, the objective of the

196 present study was to test an integrated model in which negative SCEs (guilt and shame) and

197 hubristic pride would positively predict OP, which in turn would positively predict EA. It was 
198 also expected that authentic pride would positively predict HP, which in turn would not predict 199 EA.

Method

Participants

The study utilized a convenience sample initially comprising 310 male and female runners who participated in a half-marathon race event held in a city located in southern Spain.

204 However, given that only 14 females (4.5\%) were recruited, they were excluded from the 205 analyzed sample. This meant that the final study sample comprised 296 male runners aged 206 between 18 and 70 years old $(M=40.35 ; S D=10.69)$. Their Body Mass Index $(\mathrm{BMI})$ ranged 207 from 18.61 to $32.93 \mathrm{~kg} / \mathrm{m}^{2}(M=24.33 ; S D=2.27)$. Educationally, $4.7 \%$ of the participants had 208 a middle school diploma, 31.1\% had a high school diploma, and $63.9 \%$ had a university 209 degree. According to the prevalence cut-off points proposed for the Exercise Dependence

210 Scale-Revised (Symons-Downs, Hausenblas, \& Nigg, 2004), 64.5\% of participants were 211 classified as asymptomatic, $32.1 \%$ as non-dependant-symptomatic, and $3.4 \%$ as being at-risk 212 of exercise dependence.

\section{Measures}

Demographic information. Participants gave information concerning their age, gender,

215 educational attainment, height, and weight.

Fitness-related SCES. This was assessed using the Spanish version (authors - reference

217 omitted) of the Body and Appearance Self-conscious Emotions Scale (Castonguay et al., 2016).

218 This instrument comprises four factors: shame (four items, e.g. "Inadequate when I think about 219 my fitness"), guilt (four items, e.g. "Guilty that I do not do enough to improve my fitness"), 220 authentic pride (four items, e.g. "Proud about my effort to improve my fitness"), and hubristic 221 pride (three items, e.g. "Proud of my superior fitness"). For the responses, a Likert-type scale 222 was used that ranged from 1 (never) to 5 (always). 
Passion for exercise. This was assessed using the Spanish version (Chamarro et al.,

224 2015) of the revised Passion Scale (Marsh et al., 2013). The instrument comprises two factors:

225 Harmonious Passion (six items, e.g., "My activity is well integrated into my life”) and

226 Obsessive Passion (six items, e.g., "If I could, I would only do my activity"). For the responses,

227 a Likert-type scale was used, which ranged from 1 (totally disagree) to 7 (totally agree).

228 Risk for exercise addiction. This was assessed using the Spanish version (Sicilia \&

229 González-Cutre, 2011) of the Exercise Dependence Scale-Revised (EDS-R; Symons-Downs et

230 al., 2004). This instrument consists of seven factors comprising three items each: withdrawal

231 (e.g., "I exercise to avoid feeling anxious"), continuance (e.g., "I exercise when injured"),

232 tolerance (e.g., "I continually increase my exercise frequency to achieve the desired

233 effect/benefits”), lack of control (e.g., "I am unable to reduce how long I exercise”), reduction

234 in other activities (e.g., "I would rather exercise than spend time with family/friends"), time

235 (e.g., "I spend most of my free time exercising”), and intention effects (e.g., "I exercise longer

236 than I intend to"). For the responses, a Likert-type scale was used, which ranged from 1

237 (never) and 6 (always).

238 Frequency and hours of exercise. Participants reported the number of days and number

239 of hours that they usually exercised in a typical week.

240 Procedure

After receiving the approval of the research team's ethics committee, organizers of a

242 half-marathon race event held in southern Spain were contacted to request their collaboration

243 in recruiting participants. Following this, a banner asking for volunteers to enrol in research on

244 exercise habits was posted on the official race event website. By clicking on the banner,

245 participants were redirected to a website where they were informed about (i) the non-

246 remunerated and anonymous nature of their involvement, and (ii) their right to withdraw from

247 the study at any time. After providing their informed consent, participants completed an online 
survey which included the measures described above. The automated response protocol

249 employed prevented the loss of data.

\section{Data analysis}

First, descriptive statistics, correlations between study variables, and internal consistency for the employed psychometric instruments were obtained using IBM SPSS 25. The relationships of interest were examined using structural equation modelling (SEM); namely, specifying a path analysis regression model employing the Maximum Likelihood

255 (ML) estimation method with 10,000 bootstrap replications in Mplus 7 (Muthén \& Muthén, 256 1998-2015). This procedure allowed the present researchers to maintain a reasonable ratio 257 between cases and free parameters (Kline, 2011) as well as dealing with any departures from 258 the normality and homoscedasticity assumptions (Preacher \& Hayes, 2008). In order to prevent 259 a spurious overestimation of indirect effects, all direct/indirect effects were computed

260 (Preacher \& Hayes, 2008). Usual weekly exercise hours/frequency and age were introduced as 261 covariates into the regression model. In accordance with suggestions by Preacher and Hayes 262 (2008), when specifying regression models that included a multiple mediator, the error terms of 263 the potential mediators (i.e., HP and OP) were allowed to freely correlate. Bias-corrected 264 confidence intervals (95\%), not including zero, were considered as indicative of significantly265 different-from-zero relationships at the $p<.05$ level (Preacher \& Hayes, 2008).

\section{Results}

The descriptive statistics, correlational analysis, and internal consistency are shown in

268 Table 1. The mean scores for weekly exercise frequency, authentic pride, and HP were above 269 the mid-point of their respective possible scores whereas the mean scores of the remaining 270 variables were below this point. Apart from the negative relationship found between age and 271 risk of EA, the latter was positively correlated with the remaining variables. According to 272 Cohen's criteria (1988), these relationships ranging in magnitude from small (in the case of 273 age, weekly frequency and hours of practice, authentic pride, and HP) to strong (in the case of 
274 OP). Internal consistency ranged from .84 (the shame factor of the BSE-FIT) to .93 (the 275 hubristic pride factor of the BSE-FIT and EDS-R).

A summary of the direct effects of fitness-related SCEs on HP/OP and risk of EA is

277 shown in Figure 1. A full summary of the direct and indirect effects involved are shown in

278 Tables 2 and 3. Results of the regression model showed: (i) a significant indirect shame effect

279 on risk of $\mathrm{EA}(\beta=.104, B=0.142, S E B=.069,95 \% \mathrm{CI}[0.018,0.291], p=.040)$ via OP; (ii) a

280 significant indirect effect of hubristic pride on risk of $\mathrm{EA}(\beta=.135, B=0.092, S E B=.022,95 \% \mathrm{CI}$

$281[0.051,0.140], p<.001)$ via OP; (iii) a significant direct effect of guilt on risk of EA $(\beta=.164$,

$282 B=0.155, S E B=.055,95 \% \mathrm{CI}[0.043,0.258], p=.005$ ); and (iv) a non-significant indirect/direct

283 effect of authentic pride on risk of EA. However, a significant direct effect of authentic pride

284 on HP was found $(\beta=.551, B=0.791, S E B=.095,95 \% \mathrm{CI}[0.596,0.972], p<.001)$. The model

285 explained $57 \%$ of the variance for risk of EA.

\section{Discussion}

The objective of the present study was to analyze the relationship between fitness-

related SCEs and risk of EA, and examining the mediating role of passion for exercise. It was hypothesized that guilt, shame, and hubristic pride would be positively associated with risk of

290 EA and that this relationship would be mediated by OP. At the same time, it was hypothesized

291 that authentic pride would positively predict HP, which in turn would not predict risk of EA.

292 The present study represents a significant advancement from previous research that examined

293 the relationship between appearance-related SCEs and risk of EA (Ertl et al., 2018) because the

294 research considered the relationship in the specific domain of fitness, an aspect of body-related

295 SCEs, which has demonstrated a closer relationship to exercise behaviour than to the

296 appearance aspect (Gilchrist, Pila, et al., 2018). Moreover, the study went further than previous

297 research because it simultaneously included negative and positive SCE measures and a

298 mediation analysis that provided a more nuanced insight concerning one of the potential 
motivational process underlying EA. Although OP mediating effects were not observed in the association between guilt and risk of EA, in general (and as hypothesized), the results demonstrated that not only do negative fitness-related SCEs positively predict risk of EA but also the association between positive fitness-related SCEs (i.e., hubristic pride) and risk of EA remained positive when this relationship was mediated by OP.

The results showed that the two forms of negative fitness-related SCEs (i.e., shame and guilt) had moderate positive correlations with (and showed positive effects upon) risk of EA. These findings are in line with previous studies showing that when body appraisal is incongruous with the social standards with which the individual identifies, there are positive associations with maladaptive outcomes (Castonguay et al., 2016; Ertl et al., 2018; Tagney \& Tracy, 2012). However, in line with the hypothesis raised, hubristic pride also showed a positive association with risk of EA. This is not particularly surprising given that the hubristic facet of pride has been associated with both adaptive and maladaptive outcomes (Castonguay et al., 2014; Tagney \& Tracy, 2012). In this regard, hubristic pride showed (at the same level as negative SCEs) a higher positive correlation with risk of EA than that shown by authentic pride, and was also shown to be a positive predictor of risk of EA. Previous studies have reported a positive association between both facets of fitness-related pride and frequency of moderate-vigorous exercise (Gilchrist, Pila, et al., 2018). Nonetheless, as the results of the present study appear to show, the healthy or unhealthy form of exercise to which each facet of pride appears to relate may be explained by the form of passion that the exercise arouses, and therefore by how individuals integrate exercise as part of their identity.

The outcome of the mediation analysis showed that while fitness-related hubristic pride had positive effects on OP for exercise, authentic pride had positive effects on HP.

Consequently, the results suggest that the way in which individuals interpret their social context (eliciting different facets of fitness-related pride) may affect risk of EA through a HP or OP for this activity, which could facilitate either the healthy or addictive character of the 
exercise. In fact, while OP had a positive and statistically significant effect on risk of EA, the effect of HP on risk of EA was weak and not statistically significant. These results are line with previous research (De la Vega et al., 2016; Kovacsik et al., 2018; Sicilia et al., 2018) which have shown that OP has a stronger predictive effect on risk of EA than HP, and support the notion of differentiated consequences for the two types of passion (Vallerand, 2012, 2015).

On the one hand, the results suggest that individuals experiencing pride based on what their body is capable of doing and achieving, likely regulate their exercise behavior in a flexible way (Gilchrist, Sabiston, et al., 2018). Therefore, the positive affective experience derived from fitness-related authentic pride is likely to facilitate an autonomous internalization of the exercise behavior, probably because individuals base their positive experiences on having defined success in their own skills and progress (Castonguay et al., 2016; Tagney \& Tracy, 2012). On the other hand, the results supporting the mediating role of OP for exercise in the relationship between fitness-related hubristic pride and risk of EA are novel and it may clarify the process by which this SCE may be associated with a potential maladaptive outcome such as risk of EA. Attributing a positive event to global aspects of the self (i.e., hubristic pride) may lead to socially valued exercise behavior but it also appears to result in a potential unhealthy form of exercise due to the narcissistic self-aggrandizing and boastful nature of this facet of pride (Castonguay et al., 2013; Tagney \& Tracy, 2012). Indeed, individuals who experience fitness-related hubristic pride tend to define their success on the basis of perceiving themselves of being superior to others (Castonguay et al., 2016). Consequently, it is probable that this constant comparison and desire to dominate others leads them into rigid persistence concerning exercise behavior in order to maintain their perceived social status. This is understandable if it is considered that developing OP for an activity facilitates intrapersonal conflicts (Curran, Hill, Appleton, Vallerand, \& Standage, 2015; Marsh et al., 2013), which appears appropriate when (in the exercise context) individuals are constantly comparing themselves with others and defining their fitness based on external references. When this 
351 happens, it is often difficult for individuals to find a balance between the time spent exercising

352 and other life activities, which leads to an increased risk of developing EA symptoms

353 (Hausenblas \& Symons-Downs, 2002; Symons-Downs et al., 2004; Terry, Szabo, \& Griffiths, 354 2004). Therefore, the results suggest that when explaining the relationship between positive

355 fitness-related SCEs and risk of EA, the internalization process of the behavior into the 356 individual's identity should be considered, as it would help explain why experiencing fitness357 related SCE may lead to exercise in an addictive way.

358 The analysis of the mediating role of passion also helps to understand how the 359 association between negative fitness-related SCEs and risk of EA is developed via different 360 routes. While guilt showed direct and statistically significant positive effects on risk of EA, the 361 effects of shame on risk of EA were mediated by OP. The findings suggest that experiencing 362 fitness-related shame may result in becoming passionate about exercise in an obsessive way to 363 the point that it would lead developing EA. However, experiencing fitness-related guilt does 364 not imply that exercise is an activity that is desired and loved. Indeed, the individual would not 365 value the exercise behaviour and may find it non-pleasurable, but feel compelled to do it.

366 Consequently, the results here suggest that individuals who feel guilty for not having done 367 enough to stay fit may be at risk of developing EA, without developing any type of passion for 368 exercise, and therefore without this activity becoming an integral part of their goals and values. 369 Future research should seek to identify the conditions underlying the mechanisms that may 370 explain why fitness-related shame and guilt might lead to an increased risk of EA via different 371 pathways. The results of the present study suggest several strategies that could be tried to reduce

373 the risk of developing EA. For example, by reducing self-evaluation processes through which 374 individuals compare their current fitness to ideal standards. However, the effectiveness of these 375 strategies could be limited because the assessment made of an individual's fitness could be evoked implicitly (Tagney \& Tracy, 2012), and the SCEs in this domain could be generated 
377 even if individuals are trying not to focus attention on them. Therefore, a runner who fails to

378 complete their training plan could apply strategies to avoid thinking explicitly about what this

379 event means for their fitness. However, their goals and self-representation may be activated at

380 an implicit level, eventually creating guilt or shame despite their attempt to protect themselves

381 against these emotions. Therefore, along with strategies that reduce self-evaluation pressure,

382 strategies could be applied that facilitate authentic pride emotions in the individual regarding

383 their fitness. Strategies that aim to create the attribution of success based on effort and

384 competence would help engender perceptions of prestige based on the possession of skills or

385 expertise specific to authentic pride, avoiding prestige perceptions based on superiority over 386 others.

387 Despite the novelty of the present study's results, there were some specific limitations 388 that should be highlighted when interpreting the study's findings. First, the employment of a 389 correlational and cross-sectional design does not allow the determining of causality.

390 Consequently, we were unable to determine the extent to which the observed relationships

391 reflect the effect of one variable on another over time and/or reflect ongoing stable

392 relationships among variables. Therefore, future research with longitudinal and experimental

393 designs are needed to examine the replication of results allowing statistical control for prior

394 measures of variables, and contribute to establish the directionality of the relationships found

395 in the present study. Second, the sample in the present study exclusively comprised male

396 recreational runners, so the associations examined in the present study should be examined

397 among more diverse populations and exercise practices. Finally, although it was expected (and

398 the study assumed) that fitness-related SCEs would better explain exercise behavior than other

399 body-related SCEs (e.g., those related to appearance), it would be of interest to consider the

400 analysis of SCEs in relation to both body domains and their relationship to risk of EA in the 401 same study. 
In conclusion, the results of the present study replicate previous research by suggesting 403 that OP may be strongly related to risk of EA than HP, and supports the notion that the two 404 types of passion function differently. In addition, the present study furthers the understanding 405 concerning the relationship between fitness-related SCEs and risk of EA, showing that the type 406 of passion may affect this relationship. In this sense, both fitness-related shame and hubristic 407 pride may positively lead to risk of EA, by eliciting an obsessive passion for exercise.

408 Therefore, the results suggest that the type of passion is important with respect to the 409 relationship between the fitness-related SCEs and risk of EA. 


\section{References}

411 American Psychiatric Association. (2013). Diagnostic and statistical manual of mental disorders. DSM-5 (5th Ed.). Arlington, VA: American Psychiatric Association.

413 Castonguay, A. L., Gilchrist, J. D., Mack, D. E., \& Sabiston, C. M. (2013). Body-related pride in young adults: An exploration of the triggers, contexts, outcomes and attributions. Body Image, 10(3), 335-343. https://doi.org/10.1016/j.bodyim.2013.03.001

Castonguay, A. L., Pila, E., Wrosch, C., \& Sabiston, C. M. (2015). Body-related self-conscious emotions relate to physical activity motivation and behavior in men. American Journal of Men's Health, 9(3), 209-221. https://doi.org/10.1177/1557988314537517

Castonguay, A. L., Sabiston, C. M., Crocker, P. R. E., \& Mack, D. E. (2014). Development and validation of the Body and Appearance Self-Conscious Emotions Scale (BASES). Body Image, 11(2), 126-136. https://doi.org/10.1016/j.bodyim.2013.12.006

Castonguay, A. L., Sabiston, C. M., Kowalski, K. C., \& Wilson, P. M. (2016). Introducing an instrument to measure body and fitness-related self-conscious emotions: The BSE-FIT. Psychology of Sport and Exercise, 23, 1-12. https://doi.org/10.1016/j.psychsport.2015.10.003

Chamarro, A., Penelo, E., Fornieles, A., Oberst, U., Vallerand, R. J., \& Fernández-Castro, J. (2015). Psychometric properties of the Spanish version of the Passion Scale. Psicothema,

429 Cohen, J. (1988). Statistical Power Analysis for the Behavioral Sciences (2nd ed.). Hillsdale, $430 \quad$ New Jersey: Lawrence Erlbaum.

431 Cook, R. H., Griffiths, M. D., \& Pontes, H. M. (2018). Personality factors in exercise addiction: A pilot study exploring the role of narcissism, extraversion, and agreeableness. International Journal of Mental Health and Addiction, 1-14. https://doi.org/10.1007/s11469-018-9939-z

435 Curran, T., Hill, A. P., Appleton, P. R., Vallerand, R. J., \& Standage, M. (2015). The psychology 
of passion: A meta-analytical review of a decade of research on intrapersonal outcomes. Motivation and Emotion, 39(5), 631-655. https://doi.org/10.1007/s11031-015-9503-0

De la Vega, R., Parastatidou, I. S., Ruíz-Barquín, R., \& Szabo, A. (2016). Exercise addiction in athletes and leisure exercisers: The moderating role of passion. Journal of Behavioral Addictions, 5(2), 325-331. https://doi.org/10.1556/2006.5.2016.043

Ertl, M. M., Longo, L. M., Groth, G. H., Berghuis, K. J., Prout, J., Hetz, M. C., \& Martin, J. L. (2018). Running on empty: high self-esteem as a risk factor for exercise addiction. Addiction Research and Theory, 26(3), 205-211. https://doi.org/10.1080/16066359.2017.1347257

Gilchrist, J. D., Pila, E., Castonguay, A., Sabiston, C. M., \& Mack, D. E. (2018). Body pride and physical activity: Differential associations between fitness- and appearance-related pride in young adult Canadians. Body Image, 27, 77-85. https://doi.org/10.1016/j.bodyim.2018.08.010

Gilchrist, J. D., Sabiston, C. M., Conroy, D. E., \& Atkinson, M. (2018). Authentic pride regulates runners' training progress. Psychology of Sport and Exercise, 38, 10-16. https://doi.org/10.1016/j.psychsport.2018.05.007

González-Cutre, D., \& Sicilia, Á. (2012). Motivation and exercise dependence: A study based on self-determination theory. Research Quarterly for Exercise and Sport, 83(2), 318-329.

Hausenblas, H. A., \& Symons-Downs, D. (2002). Exercise dependence: a systematic review. Psychology of Sport and Exercise, 3(2), 89-123. https://doi.org/10.1016/S14690292(00)00015-7

Kline, R. B. (2011). Principles and practice of structural equation modeling (3rd ed.). https://doi.org/10.1038/156278a0

Kovacsik, R., Griffiths, M. D., Pontes, H. M., Soós, I., de la Vega, R., Ruíz-Barquín, R., ... Szabo, A. (2018). The role of passion in exercise addiction, exercise volume, and exercise intensity in long-term exercisers. International Journal of Mental Health and Addiction, 
online, 1-12. https://doi.org/10.1007/s11469-018-9880-1

Leary, M. R. (2007). Motivational and emotional aspects of the self. Annual Review of Psychology, 58, 317-344. https://doi.org/10.1146/annurev.psych.58.110405.085658

Mack, D. E., Kouali, D., Gilchrist, J. D., \& Sabiston, C. M. (2015). Pride and physical activity: Behavioural regulations as a motivational mechanism? Psychology and Health, 30(9), 1049-1062. https://doi.org/10.1080/08870446.2015.1022547

Mageau, G. A., Carpentier, J., \& Vallerand, R. J. (2011). The role of self-esteem contingencies the distinction between obsessive and harmonious passion. European Journal of Social Psychology, 41(6), 720-729. https://doi.org/10.1002/ejsp.798

Marsh, H. W., Vallerand, R. J., Lafreniére, M., Parker, P., Morin, A., Carbonneau, N., .. Paquet, Y. (2013). Passion: Does one scale fit all? Construct validity of two-factor passion scale and psychometric invariance over different activities and languages. Psychological Assessment, 25(3), 796-809. https://doi.org/10.1037/a0032573

Muthén, L. K., \& Muthén, B. O. (n.d.). Mplus Version 7: User's guide (7th ed.). Los Angeles, CA: Muthén \& Muthén.

Parastatidou, I. S., Doganis, G., Theodorakis, Y., \& Vlachopoulos, S. P. (2014). The mediating role of passion in the relationship of exercise motivational regulations with exercise dependence symptoms. International Journal of Mental Health and Addiction, 12(4), 406419. https://doi.org/10.1007/s11469-013-9466-x

Preacher, K. J., \& Hayes, A. F. (2008). Asymptotic and resampling strategies for assessing and comparing indirect effects in multiple mediator models. Behavior Research Methods, 40(3), 879-891. https://doi.org/10.3758/BRM.40.3.879

Robins, R. W., \& Schriber, R. A. (2009). The self-conscious emotions: How are they experienced, expressed, and assessed? Social and Personality Psychology Compass, 3(6), 887-898. https://doi.org/10.1111/j.1751-9004.2009.00217.x

Sabiston, C. M., Brunet, J., Kowalski, K. C., Wilson, P. M., Mack, D. E., \& Crocker, P. R. E. 

(2010). The role of body-related self-conscious emotions in motivating women's physical activity. Journal of Sport and Exercise Psychology, 32, 417-437.

Sicilia, Á., Alcaraz-Ibáñez, M., Lirola, M.-J., Burgueño, R., \& Maher, A. (2018). Exercise motivational regulations and exercise addiction: The mediating role of passion. Journal of Behavioral Addictions, 7(2), 482-492. https://doi.org/10.1556/2006.7.2018.36

Sicilia, Á., \& González-Cutre, D. (2011). Dependence and physical exercise: Spanish validation of the Exercise Dependence Scale-Revised (EDS-R). The Spanish Journal of Psychology, 14(1), 421-431. https://doi.org/10.5209/rev_SJOP.2011.v14.n1.38

Symons-Downs, D., Hausenblas, H. A., \& Nigg, C. R. (2004). Factorial validity and psychometric examination of the Exercise Dependence Scale-Revised. Measurement in Physical Education and Exercise Science, 8(4), 183-201. https://doi.org/10.1207/s15327841mpee0804_1

Szabo, A., Demetrovics, Z., \& Griffiths, M. D. (2018). Morbid exercise behavior: Addiction or psychological escape? In H. Budde \& M. Wegner (Eds.), The exercise effect on mental health: Neurobiological mecanisms (pp. 277-311). New York, NY: Routledge.

Szabo, A., Griffiths, M. D., Demetrovics, Z., de la Vega, R., Ruíz-Barquín, R., Soós, I., \& Kovacsik, R. (2018). Obsessive and harmonious passion in physically active Spanish and Hungarian men and women: A brief report on cultural and gender differences. International Journal of Psychology, 1-6. https://doi.org/10.1002/ijop.12517

Tagney, J., \& Tracy, J. L. (2012). Self-conscious emotions. In M. Leary \& J. P. Tangney (Eds.), Handbook of self and identity (2nd ed., pp. 446-478). New York, NY: The Guildford Press.

Terry, A., Szabo, A., \& Griffiths, M. D. (2004). The exercise addiction inventory: a new brief screening tool. Addiction Research and Theory, 12(5), 489-499. https://doi.org/10.1080/16066350310001637363

Tracy, J. L., \& Robins, R. W. (2004). Putting the self into self-conscious emotions: A theoretical model. 

https://doi.org/10.1207/s15327965pli1502_01

515 Tracy, J. L., \& Robins, R. W. (2007a). The psychological structure of pride: A tale of two facets. Journal of Personality and Social Psychology, 92(3), 506-525. https://doi.org/10.1037/0022-3514.92.3.506

518 Tracy, J. L., \& Robins, R. W. (2007b). The self in self-conscious emotions: A cognitive appraisal approach. In J. L. Tracy, R. W. Robins, \& J. P. Tangney (Eds.), The self-conscious emotions: Theory and research (pp. 3-20). New York, NY: The Guildford Press.

521 Vallerand, R. J. (2008). On the psychology of passion: In search of what makes people's lives most worth living. Canadian Psychology/Psychologie Canadienne, 49(1), 1-13. https://doi.org/10.1037/0708-5591.49.1.1

524 Vallerand, R. J. (2012). Passion for sport and exercise: The Dualistic Model of Passion. In G. Roberts \& D. Treasure (Eds.), Advances in motivation in sport and exercise. Champaign, IL: Human Kinetics.

Vallerand, R. J. (2015). The psychology of passion. A dualistic model. Oxford, UK: Oxford University Press.

529 Vallerand, R. J., Blanchard, C., Mageau, G. A., Koestner, R., Ratelle, C., Léonard, M., ... Marsolais, J. (2003). Les passions de l'âme: On obsessive and harmonious passion. Journal of Personality and Social Psychology, 85(4), 756-767. https://doi.org/10.1037/0022-

533 World Health Organization. (2018). International Classification of Diseases 11th Revision. Retrieved from https://www.who.int/classifications/icd/en/ 
Table 1. Descriptive Statistics, Internal Consistency and Correlational Analysis of Study Variables (N=296)

\begin{tabular}{|c|c|c|c|c|c|c|c|c|c|c|c|c|c|c|c|}
\hline & Range $^{\mathrm{a}}$ & $M$ & $S D$ & Skewness & Kurtosis & $\alpha$ & 1 & 2 & 3 & 4 & 5 & 6 & 7 & 8 & 9 \\
\hline 1. Age & $18-70$ & 40.35 & 10.69 & -0.16 & -0.38 & - & - & & & & & & & & \\
\hline 2. Weekly Exercise Frequency & $1-7$ & 4.51 & 1,48 & -0.13 & -0.55 & - & .00 & - & & & & & & & \\
\hline 3. Weekly Exercise Hours & $1-26$ & 7.19 & 4.39 & 0.94 & 1.49 & - & $.18 * *$ & $.56 * * *$ & - & & & & & & \\
\hline 4. Shame & $1-5$ & 1.44 & 0.63 & 1.76 & 3.09 & .84 & $-.19 * *$ & -.06 & .01 & - & & & & & \\
\hline 5. Guilt & $1-5$ & 1.84 & 0.91 & 1.08 & 0.65 & .89 & $-.22 * * *$ & -.03 & .01 & $.77 * * *$ & - & & & & \\
\hline 6. Authentic pride & $1-5$ & 3.64 & 0.96 & -0.58 & -0.07 & .90 & -.02 & $.36 * * *$ & $.22 * * *$ & $-.14 *$ & -.10 & - & & & \\
\hline 7. Hubristic pride & $1-5$ & 2.77 & 1.27 & 0.12 & -1.15 & .93 & -.03 & $.33 * * *$ & $.19 * *$ & .09 & $.15^{*}$ & $.51 * * *$ & - & & \\
\hline 8. Harmonious Passion & $1-7$ & 5.02 & 1.39 & -0.70 & 0.00 & .91 & $-.13 *$ & $.23 * * *$ & $.16^{* *}$ & .00 & .01 & $.54 * * *$ & $.25 * * *$ & . & \\
\hline 9. Obsessive Passion & $1-7$ & 2.40 & 1.18 & 0.97 & 0.82 & .85 & $-.18 * *$ & $.19 * *$ & $.13 *$ & $.34 * * *$ & $.36^{* * *}$ & $.20 * *$ & $.37 * * *$ & $.21 * * *$ & - \\
\hline 10. Risk of EA (EDS-R) & $1-6$ & 2.36 & 0.86 & 0.53 & -0.20 & $.93^{\mathrm{b}}$ & $-.26^{* * *}$ & $.28 * * *$ & $.17 * *$ & $.40 * * *$ & $.44 * * *$ & $.18 * *$ & $.35 * * *$ & $.17 * *$ & $.69^{* * *}$ \\
\hline
\end{tabular}

Note. EA=Exercise Addiction, EDS-R=Exercise Dependence Scale-Revised.

${ }^{a}$ Observed for age and weekly exercise hours, possible for remaining variables.

${ }^{\mathrm{b}}$ Internal consistency values $(\checkmark)$ for the EDS-R sub-factors were .86 (Withdrawal), .84 (Continuance), .88 (Tolerance), .83 (Lack of control), .70 (Reduction in other activities), .87 (Time), and .83 (Intention effects).

$* p<.05, * * p<.01, * * * p<.001$ 
Table 2. Summary of Directs Effects of Fitness-Related Self-Conscious Emotions on Passion and Risk for Exercise Addiction

\begin{tabular}{|c|c|c|c|c|c|c|}
\hline & & & & $95 \%$ & $3 \mathrm{cCI}$ & \\
\hline & $\beta$ & $B$ & $S E B$ & Lower & Upper & $p$-value \\
\hline Shame $\rightarrow$ HP & .068 & 0.148 & .159 & -0.156 & 0.468 & .350 \\
\hline Guilt $\rightarrow$ HP & -.010 & -0.016 & .106 & -0.234 & 0.185 & .881 \\
\hline Authentic Pride $\rightarrow$ HP & .551 & 0.791 & .095 & 0.596 & 0.972 & $<.001$ \\
\hline Hubristic Pride $\rightarrow$ HP & -.052 & -0.057 & .072 & -0.196 & 0.084 & .430 \\
\hline Weekly Exercise Frequency $\rightarrow$ HP & .024 & 0.023 & .051 & -0.078 & 0.125 & .659 \\
\hline Weekly Exercise Hours $\rightarrow$ HP & .056 & 0.018 & .019 & -0.019 & 0.053 & .337 \\
\hline Age $\rightarrow$ HP & -.124 & -0.016 & .006 & -0.017 & -0.003 & .008 \\
\hline Shame $\rightarrow$ OP & .197 & 0.367 & .168 & 0.044 & 0.701 & .029 \\
\hline Guilt $\rightarrow$ OP & .155 & 0.201 & .124 & -0.038 & 0.450 & .105 \\
\hline Authentic Pride $\rightarrow$ OP & .072 & 0.088 & .073 & -0.057 & 0.233 & .227 \\
\hline Hubristic Pride $\rightarrow$ OP & .256 & 0.237 & .055 & 0.128 & 0.346 & $<.001$ \\
\hline Weekly Exercise Frequency $\rightarrow$ OP & .073 & 0.058 & .061 & -0.062 & 0.176 & .341 \\
\hline Weekly Exercise Hours $\rightarrow$ OP & .034 & 0.009 & .020 & -0.028 & 0.049 & .640 \\
\hline Age $\rightarrow$ OP & -.103 & -0.011 & .006 & -0.024 & 0.000 & .064 \\
\hline Shame $\rightarrow$ EDS-R & .082 & 0.112 & .078 & -0.036 & 0.273 & .150 \\
\hline Guilt $\rightarrow$ Risk of EA & .164 & 0.155 & .055 & 0.043 & 0.258 & .005 \\
\hline Authentic Pride $\rightarrow$ Risk of EA & .031 & 0.028 & .052 & -0.073 & 0.130 & .596 \\
\hline Hubristic Pride $\rightarrow$ Risk of EA & .060 & 0.041 & .035 & -0.028 & 0.107 & .238 \\
\hline $\mathrm{HP} \rightarrow \mathrm{EDS}-\mathrm{R}$ & -.031 & -0.020 & .031 & -0.081 & 0.042 & .534 \\
\hline OP $\rightarrow$ Risk of EA & .528 & 0.387 & .038 & 0.313 & 0.462 & $<.001$ \\
\hline Weekly Exercise Frequency $\rightarrow$ Risk of EA & .162 & 0.094 & .010 & 0.032 & 0.158 & .004 \\
\hline Weekly Exercise Hours $\rightarrow$ Risk of EA & .018 & 0.004 & .033 & -0.015 & 0.025 & .734 \\
\hline Age $\rightarrow$ Risk of EA & -.117 & -0.009 & .004 & -0.017 & -0.003 & .008 \\
\hline
\end{tabular}

Note. $B=$ Unstandardized estimates; $S E=$ Standard error; 舫 $=$ Standardized estimates; $\mathrm{BcCI}=$ Bias corrected Confidence Interval, $\mathrm{HP}=$ Harmonious passion, $\mathrm{OP}=$ Obsessive passion, $\mathrm{EA}=$ Exercise addiction. Results derived from a 10,000 resamples bootstrapping analysis. Bolded estimates indicate statically significant $(p<.05)$ indirect effects. 
Table 3. Summary of Indirect Effects of Fitness-Related Self-Conscious Emotions on Risk for Exercise Addiction via Passion

\begin{tabular}{lcrrrrrr}
\hline & & & & \multicolumn{2}{c}{$95 \%$ BcCI } & \\
Path & $\beta$ & $B$ & $S E B$ & Lower & Upper & $p$-value \\
\hline Shame $\rightarrow \mathrm{HP} \rightarrow$ Risk of EA & -.002 & -0.003 & .007 & -0.029 & 0.005 & .687 \\
Shame $\rightarrow$ OP $\rightarrow$ Risk of EA & $\mathbf{. 1 0 4}$ & $\mathbf{0 . 1 4 2}$ & $\mathbf{. 0 6 9}$ & $\mathbf{0 . 0 1 8}$ & $\mathbf{0 . 2 9 1}$ & $\mathbf{. 0 4 0}$ \\
Guilt $\rightarrow \mathrm{HP} \rightarrow$ Risk of EA & .000 & 0.000 & .004 & -0.006 & 0.012 & .938 \\
Guilt $\rightarrow \mathrm{OP} \rightarrow$ Risk of EA & .082 & 0.078 & .048 & -0.013 & 0.176 & .105 \\
Authentic Pride $\rightarrow \mathrm{HP} \rightarrow$ Risk of EA & -.017 & -0.015 & .025 & -0.064 & 0.034 & .535 \\
Authentic Pride $\rightarrow \mathrm{OP} \rightarrow$ Risk of EA & .038 & 0.034 & .029 & -0.020 & 0.096 & .242 \\
Hubristic Pride $\rightarrow \mathrm{HP} \rightarrow$ Risk of EA & .002 & 0.001 & .003 & -0.002 & 0.014 & .724 \\
Hubristic Pride $\rightarrow \mathbf{O P} \rightarrow$ Risk of EA & $\mathbf{. 1 3 5}$ & $\mathbf{0 . 0 9 2}$ & $\mathbf{. 0 2 2}$ & $\mathbf{0 . 0 5 1}$ & $\mathbf{0 . 1 4 0}$ & $<.001$ \\
\hline
\end{tabular}

Note. $B=$ Unstandardized estimates; $S E=$ Standard error; фь $=$ Standardized estimates; $\mathrm{BcCI}=$ Bias corrected Confidence Interval, $\mathrm{HP}=$ Harmonious passion, $\mathrm{OP}=$ Obsessive passion, $\mathrm{EA}=$ Exercise addiction. Results derived from a 10,000 resamples bootstrapping analysis. Bolded estimates indicate statically significant $(p<.05)$ indirect effects. 


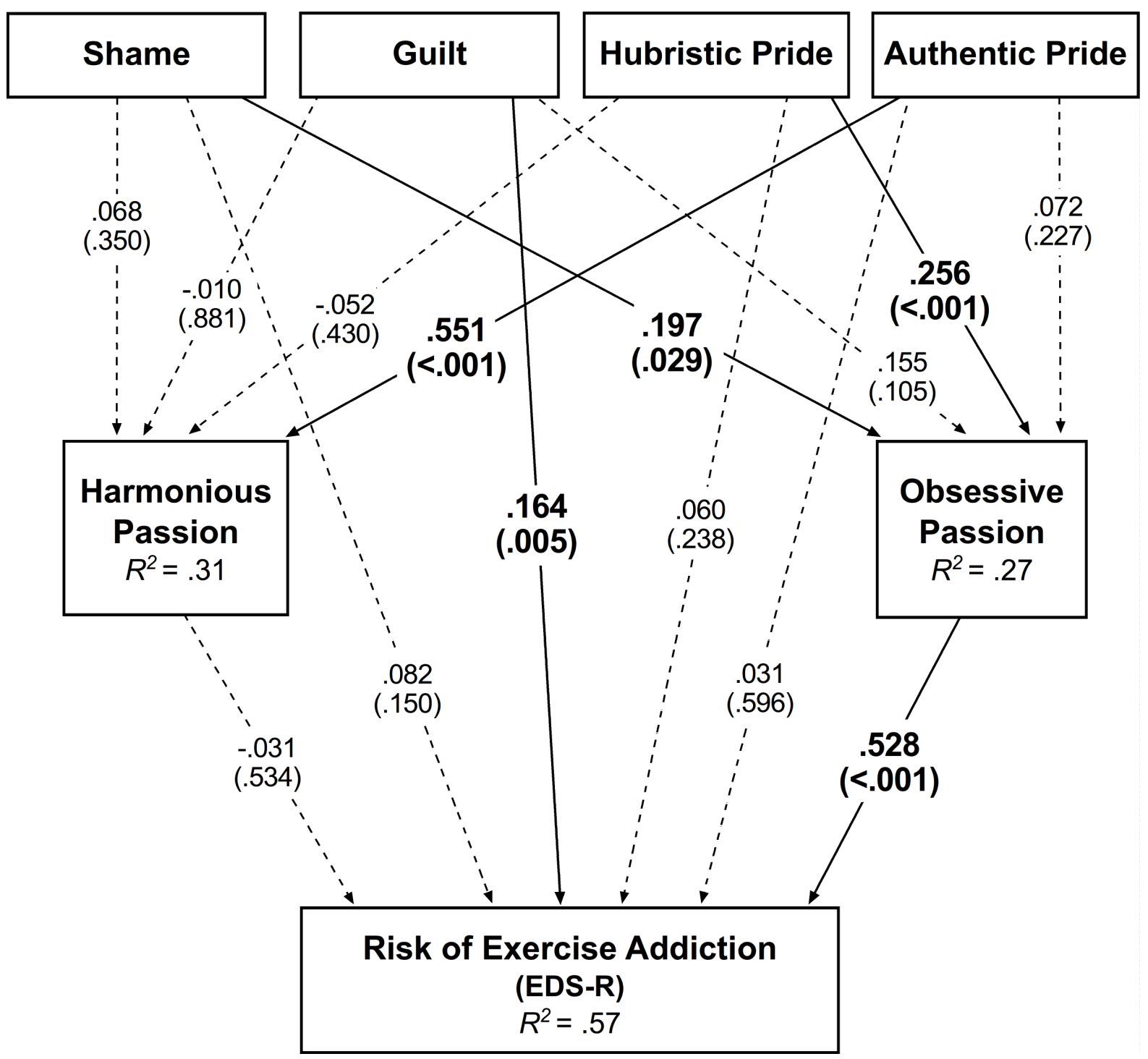

Figure 1. Summary of Standardized Directs Effects of Fitness-Related Self-Conscious

Emotions on Passion and Risk for Exercise Addiction. For clarity, the effects of weekly exercise hours/frequency and age on endogenous variables are not depicted. EDS-R=Exercise Dependence Scale-Revised. Results derived from a 10,000 resamples bootstrapping analysis. Continuous lines and bolded estimates indicate statically significant $(p<.05)$ effects. Values inside brackets reflects specific $p$-values. 